\title{
Cholecysto-duodenal fistula as the source of upper gastrointestinal bleeding
}

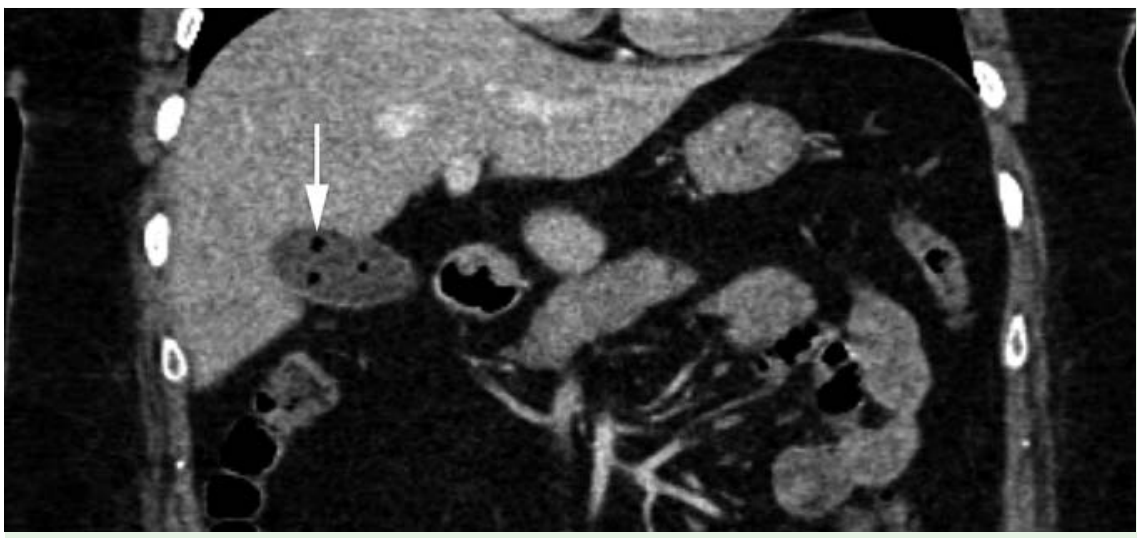

Fig. 1 Coronal portal phase computed tomography image demonstrating low attenuation gallstones (arrow) in a normal gallbladder.

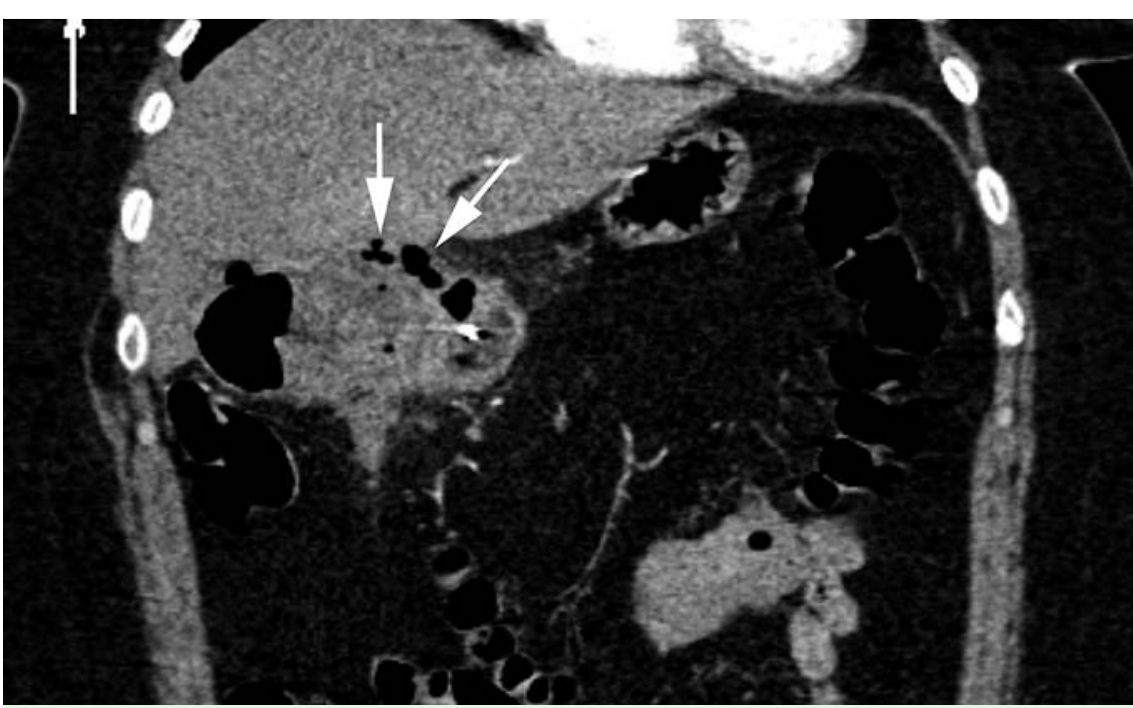

Fig. 3 Curved coronal portal phase computed tomography image demonstrating a gas-filled biliaryenteric fistula extending from the gallbladder to the duodenum (arrows). There is also gas in the gallbladder. A high attenuation metallic hemostasis clip can be seen at the medial end of the fistula.

A 44-year-old woman was admitted with recurrent hematemesis. She had a history of intermittent upper abdominal pain, which was investigated by computed tomography (CT) scan 1 year prior to the presentation ( $\bullet$ Fig. 1 ). She was taking aspirin for ischemic heart disease.

On examination, her heart rate was $110 \mathrm{bpm}$ and she had postural hypotension. She was febrile $\left(38.7^{\circ} \mathrm{C}\right)$ and had epigastric tenderness. Blood results were abnormal: white blood cells $17.0 \times 10^{3}$ cells/ $\mu \mathrm{L}, \mathrm{C}$-reactive protein $136 \mathrm{mg} / \mathrm{L}$, and alkaline phosphatase 515 IU/L (normal range 70-300IU/L). Glasgow-Blatchford and Rockall scores were elevated at 11 and 8 , respectively. Findings at gastrointestinal endoscopy and CT scan are shown in $\checkmark$ Fig. 2 and $\bullet$ Fig. 3.

Biliary-enteric fistula (BEF) is a rare cause of upper gastrointestinal bleeding. Cholecysto-duodenal fistula (CDF) is the commonest type of BEF [1]. The common causes of CDF include gallstones, peptic ulcer disease, malignancy, and trauma/ surgery. Definitive management is cholecystectomy, resection of the fistula, and intraoperative cholangiography. Diagnosis is made by CT, endoscopic retrograde cholangiopancreatography, or laparoscopic cholecystectomy [2]. Proximal CDFs located in the posterior wall of the duodenal
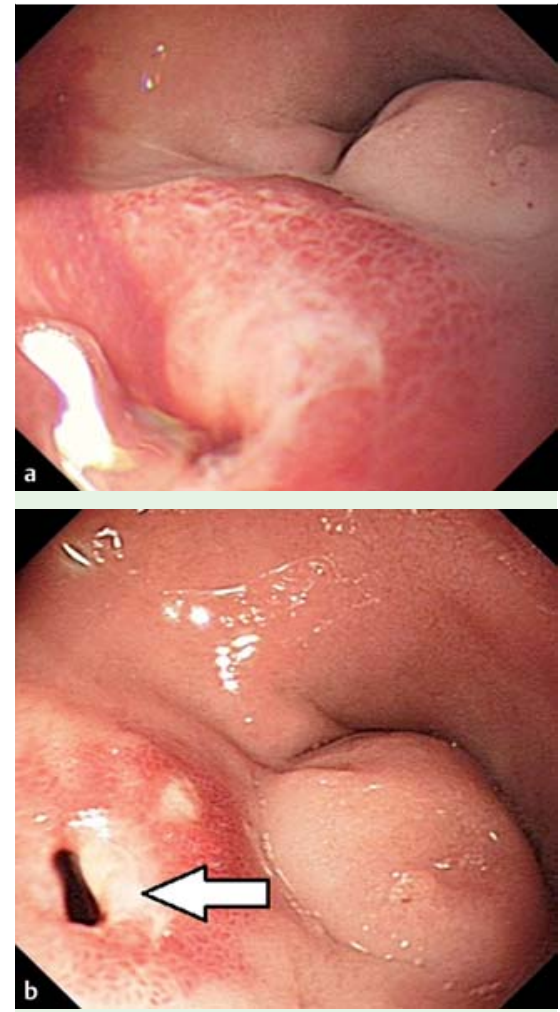

Fig. 2 Findings at endoscopy. a Bleeding lesion noted on endoscopy in the first part of the duodenum. b Fistulous opening in the posterior wall of duodenal bulb after endoscopic treatment (arrow).

bulb are usually secondary to peptic ulcer disease whereas distal CDFs, which are located in the periampullary region, connect to the distal $2 \mathrm{~cm}$ of the bile duct and are more commonly associated with biliary stones [3].

Our patient had symptoms of biliary colic and had gallbladder calculi on initial CT scan. She had recurrent hematemesis during episodes of cholangitis. She was treated conservatively with antibiotics and underwent successful elective open cholecystectomy with repair of the CDF. BEFs involving the duodenal bulb secondary to cholelithiasis are uncommon. CT allows visualization of the fistulas, air in the bile duct, and contraction of the gallbladder, and differentiates between cholecysto-enteric and choledocho-enteric fistulas [4]. We believe that this case highlights the importance of CT imaging in patients with upper gastrointestinal bleeding and unusual endoscopic findings. 
Endoscopy_UCTN_Code_CCL_1AB_2AZ_3AZ

Competing interests: None

N. Mohammed ${ }^{1}$, E. M. Godfrey², V. Subramanian'

${ }^{1}$ Department of Gastroenterology, St. James's University Hospital NHS Trust, Leeds, United Kingdom

2 Department of Radiology, St. James's University Hospital NHS Trust, Leeds, United Kingdom

\section{References}

1 Glenn F, Reed C, Grafe WR. Biliary enteric fistula. Surg Gynecol Obstet 1981; 153: 527 531

2 Leung E, Kumar P. Bilo-enteric fistula (BEF) at laparoscopic cholecystectomy: review of ten year's experience. Surgeon 2010; 8: 67-70

3 Stagnitti F, Mongardini M, Schillaci $F$ et al. [Spontaneous biliodigestive fistulae. The clinical considerations, surgical treatment and complications.] [Article in Italian]. G Chir 2000; 21: 110-117

4 Shimono T, Nishimura K, Hayakawa K. CT imaging of biliary enteric fistula. Abdom Imaging 1998; 23: 172-176

\section{Bibliography}

DOI http://dx.doi.org/

10.1055/s-0033-1344418

Endoscopy 2013; 45: E250-E251

(c) Georg Thieme Verlag KG

Stuttgart · New York

ISSN 0013-726X

\section{Corresponding author}

N. Mohammed, MD

Department of Gastroenterology St. James's University Hospital NHS Trust Beckett Street

Leeds LS9 7TF

UK

Fax: +44-1132-068851

Noor.Mohammed@doctors.org.uk 